\title{
Pharmacological Studies of Different Fractions of Litsea monopetala Roxb.
}

\author{
Israt Jahan Bulbul, Mohammad A. Rashid and Mohammad Rashedul Haque \\ Department of Pharmaceutical Chemistry, Faculty of Pharmacy, University of Dhaka \\ Dhaka-1000 Bangladesh
}

(Received: January 13, 2020; Accepted: January 28, 2020; Published: January 30, 2020)

\begin{abstract}
Now-a-days formulations based on natural products getting attention because of their low or absence of toxicity, complete biodegradability, availability from natural sources and their low-cost compared to those of compounds obtained by total chemical synthesis (Abbott, 1995). In developing countries like Bangladesh, the study for biological activities from locally available plants have been raised significantly to reduce public health costs. From this perspective, a locally available medicinal plant of Bangladesh, was selected for this study to explore its pharmacological potential.
\end{abstract}

Litsea monopetala Roxb. (Synonym: Litsea polyantha Juss.) belonging to the family Lauraceae which is locally known as Bara Kukurchita, Mendaphuri, Sukurja, Uruijja (Chittagong), Akorma, Lalkhori (Dinajpur) and Huoria (Sylhet). It is distributed in the forests of Chittagong, Chittagong Hill Tracts, Sylhet and Sal forests of Gazipur, Madhupur, Dinajpur and also found in the villages throughout the country. L. monopetala is a small or medium sized evergreen tree with 7.5-23 cm long leaves, elliptic-oblong, usually rounded at both ends, pubescent at the beneath. Flowers are small, pale greenish yellow, sessile or subsessile, about 5-6 together in rounded umbellate heads, $1-1.3 \mathrm{~cm}$ across, solitary or clustered on dwarf side shoots. Fruit is $10 \mathrm{~mm}$ long, ovoid and black. Traditionally, water extract of the bark is given with sugar to treat diarrhea and dysentery while powder of the bark is applied to body for pains arising from blows or bruises or from hard work (Yusuf et al., 2009).
Different extracts from bark, aerial parts, leaves, flowers and fruits of the plant have been reported for its biological activities as well as the presence of phytochemicals. The extract of dried bark and aerial parts of $L$. monopetala has antidiarrheal and antidepressant activity (Poonia et al., 2007). Phenolic compounds extracted from L. monopetala bark have antioxidant activity (Arfan et al., 2008). The leaf extract possesses antimicrobial (Ahmad et al., 2012; Hasan et al., 2016), clot lysis, antiinflammatory (Ahmad et al., 2012), analgesic (Ghosh and Sinha 2010) and antioxidant and antidiarrheal (Dutta, 1968) properties. The presence of eugenol, chalcone and its derivatives (Ghosh and Sinha 2010), $\beta$-sitosterol and actinodaphnine (Choudhury et al., 1997) in bark extracts, $\quad \alpha$-caryophyllene alcohol, pentacosane, caryophyllene oxide, humulene oxide and tricosane in the flower oil, decanal, nonanol and capric acid in fruit oil and tetradecanal, tridecanol, myristic acid and tridecanal in bark oil (Banerji et al., 1968) have been reported from $L$. monopetala. An arabinoxylanis reported from the mucilage of the leaves of L. monopetala (Bulbul et al., 2016).

As part of our continuing investigation on medicinal plants of Bangladesh (Bulbul et al., 2017; Kupchan and Tosu, 1973) the different fractions (petroleum, chloroform and ethylacetate soluble fractions) of L. monopetala leaves were studied for the preliminary phytoconstituents, antioxidant potential in terms of total phenolic content and free radical scavenging, antimicrobial, analgesic,

Correspondence to: Mohammad Rashedul Haque; E-mail: haquemr@du.ac.bd

DOI: https://doi.org/10.3329/bpj.v23i1.45322 
hypoglycemic and CNS depressant activities and we here in report the results of one findings.

The phytochemical screening (Table 1) revealed that alkaloids, tannins, saponins, cardiac glycosides, anthraquinone glycosides are present in different partitionates of $L$. monopetala leaf, whereas carbohydrates and reducing sugar were absent in all the partitionates.

The total phenolic content of the extractives of leaves of $L$. monopetala was found in the range of $3.35 \pm 0.5$ to $4.96 \pm 0.23) \mathrm{mg}$ of $\mathrm{GAE} / \mathrm{g}$ of extractives, with the highest amount of phenolics $(4.96 \pm 0.23)$ being observed in the petroleum ether soluble fraction (Table 2). In the DPPH free radical scavenging assay, the petroleum ether soluble fraction of leaves of $L$. monopetala showed maximum free radical scavenging activity having $\mathrm{IC}_{50}$ value of $59.76 \pm 0.71$ $\mu \mathrm{g} / \mathrm{ml}$ while the standard ascorbic acid showed $\mathrm{IC}_{50}$ value of $51.54 \pm 0.17 \mu \mathrm{g} / \mathrm{ml}$ (Table 2).

Table 1. Preliminary phytochemical analysis of different partitionates of $L$. monopetala leaf.

\begin{tabular}{|c|c|c|c|c|c|}
\hline S1. No & Test & Reagent & PESF & CSF & EASF \\
\hline 1 & Alkaloids & $\begin{array}{l}\text { Mayer's, Hager's, Wagner's, } \\
\text { Dragendorff's }\end{array}$ & + & + & + \\
\hline 2 & Tannins & Lead acetate & + & + & + \\
\hline 3 & Saponins & Water + shake & + & + & + \\
\hline 4 & Cardiac glycosides & $\begin{array}{l}\text { Glacial acetic acid }+ \text { Ferric Chloride }+ \\
\text { Conc. Sulphuric acid }\end{array}$ & + & + & + \\
\hline 5 & Anthraquinone glycosides & Brontrager's reagent & + & + & + \\
\hline 6 & Carbohydrates & Molisch's, Fehling's, Barfoed's reagents & - & - & - \\
\hline 7 & Reducing sugars & Benedict's solution & - & - & - \\
\hline
\end{tabular}

Table 2. Total phenolic content, DPPH free radical scavenging activity of L. monopetala.

\begin{tabular}{lcc}
\hline Plant sample/ standard & $\begin{array}{c}\text { Total phenolic content } \\
(\mathrm{mg} \text { of GAE/gm of extract) }\end{array}$ & $\begin{array}{c}\text { DPPH free radical scavenging activity } \\
\left(\mathrm{IC}_{50} \mu \mathrm{g} / \mathrm{ml}\right)\end{array}$ \\
\hline PESF & $4.96 \pm 0.23$ & $59.76 \pm 0.71$ \\
CSF & $3.35 \pm 0.55$ & $66.80 \pm 0.12$ \\
EASF & $3.93 \pm 0.63$ & $60.40 \pm 0.15$ \\
Ascorbic acid & & $51.54 \pm 0.17$ \\
\hline
\end{tabular}

$\mathrm{PESF}=$ Pet-ether soluble fraction; $\mathrm{CSF}=$ Chloroform soluble fraction; $\mathrm{EASF}=$ Ethyl acetate soluble fraction.

The antibacterial activity of different fraction (EASF) demonstrated good antimicrobial partitionates of $L$. monopetala has been summarized activity against $\quad B$. subtilis $\left(\begin{array}{llll}15.67 & \mathrm{~mm}\end{array}\right), \quad B$. in table 3. The pet-ether soluble fraction (PESF) of $L$. Megaterium $(16.33 \mathrm{~mm})$, B. cereus $(15.67 \mathrm{~mm})$ and monopetala showed moderate antimicrobial activity $\quad$ P. aeruginosa $(15.33 \mathrm{~mm})$ whereas mild to moderate against Bacillus subtilis $(13.67 \mathrm{~mm})$, B. megaterium $(13.00 \mathrm{~mm})$ and Vibrio parahemolyticus $(12.67 \mathrm{~mm})$. The chloroform soluble fraction (CSF) revealed good activity against $B$. subtilis $(16 \mathrm{~mm})$ and $V$. parahemolyticus $(15.33 \mathrm{~mm})$. The CSF showed mild to moderate activity (9 to $12 \mathrm{~mm}$ ) against the remaining organisms. The ethyl acetate soluble activity against other organisms.

The leaf extract of $L$. monopetala showed significant peripheral $(p<0.05)$ analgesic activity at both doses of 100 and $200-\mathrm{mg} / \mathrm{kg}$ body weight with writhing inhibition of 33.89 and $38.98 \%$, respectively (Table 4). 
The effects of methanol extract of $L$. monopetala leaves on blood glucose level in alloxan induced diabetic rats are shown in table 5 which represents that the blood glucose level significantly decreased $(\mathrm{p}<0.05)$ on the $5^{\text {th }}$ and $7^{\text {th }}$ day of treatment after administration of both the 300 $\mathrm{mg} / \mathrm{kg} /$ day and $500 \mathrm{mg} / \mathrm{kg} /$ day doses of the extract.

Table 3. Zones of growth inhibition ( $\mathrm{mm})$ showing antibacterial activity for three fractions of L. monopetala.

\begin{tabular}{lllll}
\hline Bacterial Strain & PESF & CSF & EASF & Kanamycin/Griseofulvin \\
\hline Bacillus subtilis & $13.67 \pm 0.47$ & $16.00 \pm 0.82$ & $15.67 \pm 0.47$ & $31.33 \pm 0.94$ \\
B. megaterium & $13.00 \pm 0.82$ & $11.33 \pm 1.25$ & $16.33 \pm 0.47$ & $32.00 \pm 0.82$ \\
B. cereus & $10.33 \pm 0.47$ & $9.67 \pm 0.94$ & $15.67 \pm 0.94$ & $30.67 \pm 0.94$ \\
Staphylococcus aureus & $8.33 \pm 0.94$ & $10.67 \pm 0.94$ & $11.00 \pm 0.82$ & $32.67 \pm 0.47$ \\
Sarcina lutea & $9.00 \pm 0.82$ & $12.33 \pm 0.47$ & $14.33 \pm 0.47$ & $30.33 \pm 0.47$ \\
Escherichia coli & $8.00 \pm 1.41$ & $11.00 \pm 0.82$ & $10.00 \pm 0.82$ & $29.33 \pm 0.94$ \\
Vibrio mimicus & $8.00 \pm 0.82$ & $11.67 \pm 0.47$ & $14.67 \pm 0.47$ & $30.33 \pm 1.25$ \\
V. parahemolyticus & $12.67 \pm 0.47$ & $15.33 \pm 0.47$ & $14.00 \pm 0.82$ & $28.33 \pm 0.47$ \\
Pseudomonas aeruginosa & $10.33 \pm 0.47$ & $11.00 \pm 0.82$ & $15.33 \pm 0.47$ & $31.33 \pm 0.94$ \\
Salmonella paratyphi & $11.67 \pm 0.94$ & $11.67 \pm 0.47$ & $12.67 \pm 0.47$ & $28.33 \pm 0.47$ \\
Shigella dysenteriae & $10.00 \pm 0.82$ & $11.33 \pm 1.25$ & $12.67 \pm 0.94$ & $30.67 \pm 0.94$ \\
S. boydii & $9.00 \pm 0.82$ & $9.67 \pm 0.47$ & $9.67 \pm 0.47$ & $30.33 \pm 0.47$ \\
Candida albicans & $8.67 \pm 0.47$ & $11.67 \pm 0.47$ & $14.33 \pm 0.47$ & $31.67 \pm 1.25$ \\
Asperagillus niger & $7.67 \pm 0.94$ & $11.33 \pm 0.94$ & $10.00 \pm 0.82$ & $29.67 \pm 1.25$ \\
Sacharomyeces cereveceae & $10.00 \pm 0.82$ & $11.00 \pm 0.82$ & $10.67 \pm 0.47$ & $28.67 \pm 0.47$ \\
\hline
\end{tabular}

Values for zone of growth inhibition are presented as mean $\pm \mathrm{SD}$; disc diameter is $5.0 \mathrm{~mm}$

Table 4. Peripheral analgesic activity of methanolic crude extract of $L$. monopetala.

\begin{tabular}{llll}
\hline Group & Treatment, dose \&route & No. of writhing & \% of inhibition \\
\hline Group I (Control) & Saline water, tween 80, p.o & $14.75 \pm 3.21$ & - \\
Group II (Standard) & Indomethacin, $10 \mathrm{mg} / \mathrm{kg}$, p.o & $3.00 \pm 1.20^{* * *}$ & $79.66 \%$ \\
Group III & L. monopetala $100 \mathrm{mg} / \mathrm{kg}$, p.o & $9.75 \pm 3.21^{*}$ & $33.89 \%$ \\
Group IV & L. monopetala $200 \mathrm{mg} / \mathrm{kg}$, p.o & $9.00 \pm 1.25^{*}$ & $38.98 \%$ \\
\hline
\end{tabular}

All values are expressed as mean \pm SEM, $(n=6)$; One way Analysis of Variance (ANOVA) followed by Dunnet's test. $* * * \mathrm{p}<0.001, * * \mathrm{p}<0.01, * \mathrm{p}<0.05$, significant compared to control.

Table 5. Hypoglycemic Activity of methanolic crude extract of $L$. monopetala

\begin{tabular}{lcccc}
\hline Groups & \multicolumn{4}{c}{ Blood glucose level } \\
\cline { 2 - 5 } & $1^{\text {st }}$ Day & $3^{\text {rd }}$ Day & $5^{\text {th }}$. Day & $7^{\text {th }}$. Day \\
\hline Control (Non-diabetic) & $5.20 \pm 0.17$ & $5.01 \pm 0.13$ & $5.50 \pm 0.35$ & $4.87 \pm 0.26$ \\
Control (Diabetic) & $10.65 \pm 0.22$ & $10.16 \pm 0.49$ & $12.54 \pm 0.32$ & $11.93 \pm 0.51$ \\
STD (Metformin HCl) $50 \mathrm{mg} / \mathrm{kg} /$ day & $12.46 \pm 0.67$ & $5.53 \pm 0.27^{* *}$ & $4.46 \pm 0.14^{* *}$ & $4.26 \pm 0.32^{* *}$ \\
MELM 300 mg/kg/day & $9.8 \pm 0.52$ & $7.00 \pm 0.62$ & $6.55 \pm 0.35^{*}$ & $6.00 \pm 0.27^{* *}$ \\
MELM 500 mg/kg/day & $11.2 \pm 0.12$ & $6.50 \pm 0.62$ & $5.25 \pm 0.05^{* *}$ & $5.00 \pm 0.20^{* *}$ \\
\hline
\end{tabular}

All values are expressed as mean \pm SEM, $(n=6)$; One way Analysis of Variance (ANOVA) followed by Dunnet's test. $* * * \mathrm{p}<0.001, * * \mathrm{p}<0.01, * \mathrm{p}<0.05$, significant compared to control.

In CNS depressant activity test, the extract showed a decrease in locomotion in the test animals. The number of crossing hole from one chamber to another by mice of the control group remained almost steady from 0 minute to 120 minutes (Table 6). But the three different fractionates at $500 \mathrm{mg} / \mathrm{kg}$ dose 
showed significant and gradual decrease of presence of CNS depressant potential in $L$. movement from 0 to $120 \mathrm{~min}$, which suggest the monopetala.

Table 6. CNS depressant activity of methanol extract of $L$. monopetala leaves.

\begin{tabular}{|c|c|c|c|c|c|c|}
\hline \multirow[t]{2}{*}{ Treatment } & \multirow[t]{2}{*}{ Doses } & \multicolumn{5}{|c|}{ Number of Movements } \\
\hline & & $0 \mathrm{~min}$ & $30 \mathrm{~min}$ & $60 \mathrm{~min}$ & $90 \mathrm{~min}$ & $120 \mathrm{~min}$ \\
\hline $\begin{array}{l}1 \% \text { tween } 80 \text { in saline } \\
\text { water (Control) }\end{array}$ & $10 \mathrm{ml} / \mathrm{kg}$ & $13.50 \pm 1.19$ & $14.00 \pm 1.29$ & $14.25 \pm 0.85$ & $14.00 \pm 1.08$ & $13.50 \pm 0.29$ \\
\hline Diazepam (Standard) & $1 \mathrm{mg} / \mathrm{kg}$ & $10.75 \pm 0.48$ & $6.75 \pm 0.25^{*}$ & $4.00 \pm 0.48^{*}$ & $2.75 \pm 0.48$ & $1.50 \pm 0.29 *$ \\
\hline MESF & $500 \mathrm{mg} / \mathrm{kg}$ & $6.75 \pm 0.99 * * *$ & $5.00 \pm 0.82 * * *$ & $4.00 \pm 1.05^{* * *}$ & $4.00 \pm 0.82 * * *$ & $2.25 \pm 0.73^{*}$ \\
\hline
\end{tabular}

All values are expressed as mean \pm SEM, ( $n=6$ ); One-way Analysis of Variance (ANOVA) followed by Dunnet's test. $* * * \mathrm{p}<0.001, * * \mathrm{p}<0.01, * \mathrm{p}<0.05$, significant compared to control.

It is clearly evident from the above findings that different partitionates of $L$. monopetala leaves contain alkaloids, tannins, saponins, cardiac glycosides, antraquinone glycosides and have significant free radical scavenging, moderate antimicrobial activities and significant peripheral analgesic. The plant also exhibited comparable hypoglycemic potential on the $5^{\text {th }}$ and the $7^{\text {th }}$ day of treatment. It has been reported that the leaves of $L$. monopetala are used to slow aging process, treat infectious diseases, pain, insomnia and other health disorders. Our findings rationalize some of the traditional uses of the plant species. Therefore, the plant is a good candidate for further chemical investigations to isolate the active constituents.

\section{References}

Abbott, A. 1995. Life sciences gain favour in patents. Nature. 375, 619.

Ahmad, A., Islam, M.T., Sultana, I., Mahmood, A., Hossain, J.A., Homa, Z., Ibrahim, M. and Chowdhury, M.M.U. 2012. Pharmacological and phytochemical screening of ethanol extract of Litsea monopetala (Roxb.) Pers. IOSR J. Pharm. 2, 398-402.

Arfan, M., Amin, H., Kosinska, A., Karamac, M. and Amarowicz, R. 2008. Antioxidant activity of phenolic fractions of Litsea monopetala (Persimon-leaved Litsea) bark extract. Pol. J. Food Nutr. Sci. 58, 229233.

Banerji, N., Sarkar K.K. and Das, A.K. 1986. An arabinoxylan from the mucilage of the leaves of Litsea polyantha. Carbohyd. Res., 147, 165-168.
Bulbul, I.J., Fashiuddin S.B., Haque M.R., Sultan M.Z. and Rashid M.A. 2017. Anti-nociceptive and antiinflammatory activities of Crotalaria pallida Aiton (Fam: Fabaceae) leaves. Bangladesh Pharm. J. 20, 165-171.

Bulbul, I.J., Khan, M.F., and Rashid, M.A. 2016. Analgesic and central nervous system depressant activities of methanol extract of Ziziphus rugosa Lam. Leaves. Afr. J. Pharm. Pharmacol. 10, 849-853.

Choudhury, S.N., Ghosh, A.C., Choudhury, M. and Leclercq, P.A., 1997. Essential oils of Litsea monopetala (Roxb.) Pers. J. Essent. Oil Res. 9, 635639.

Dutta, T., 1968. Investigations on Litsea polyantha, isolation and identification of actinodaphnine. $J$. Indian Chem. Soc. 45, 987-991.

Ferdous, M.R, Ashrafudoulla, M., Hossain, M.S., and Bellah S.F. 2018. Evaluation of antioxidant, analgesic and antidiarrheal activities of methanolic extract of Litsea monopetala (Roxb.) leaves. Clin. Pharmacol. Biopharm. 7, 1-6.

Ghosh, M. and Sinha, B.N. 2010. GC-MS studies on the bark extracts of Litsea polyantha Juss. Middle-East J. Sci. Res. 5, 441-444.

Hasan, M.F., Iqbal, M.A. and Uddin, M.S. 2016. Antibacterial and antifungal activity of Litsea monopetala leaves on selected pathogenic strains. Euro. J. Med. Plant. 12, 1-8.

Poonia, B.S., Sasmal D. and Mazumdar, P.M. 2007. Antidiarrheal activity of methanol extract of Litsea polyantha bark in mice. Fitoterapia 78, 1710-174.

Yusuf, M., Begum, J., Hoque, M.N. and Chowdhury, J.U. 2009. Medicinal Plants of Bangladesh (revised and enlarged). Bangladesh Council of Scientific and Industrial Research Laboratories, Chittagong, Bangladesh. p. 517. 